\section{MALIGNANT CHOLERA.}

BLFFDING-COLD SALT AND WATER IN GALLONS.-MERCURIAL FRICTIONS, \&c.

Is reply to the request of the Central Board of Health, for a short account of the treatment of cholera, I beg to state that bleeding was found to be most beneficial in all cases, where I was called sufficiently early to adopt it, that is, before the stage of collupse, and that it was decidedly injurious after.

In real cases of what is called cholera, where there was vomiting of watery fuid like cold chicken broth, and evacuations of the very same appearance, neither feculent or bilious, after bleeding, an ounce of muriate of soda in a tumbler of hot water, as an emetic, then a teaspoonful of salt in a tumbler of cold water, to be drunk as often and as freely as the patient chooses, with the saline effervescents, lime-water and milk, and toast-and-water; a solution of isinglass per anum, frequently, with 20 or 50 drops tr. opii in it. It is astonishing how much toast and water and cold salt and water was taken by some of them; three or four gallons in a night were taken and rejected; but I found those who drank most salt and water began to have a yellowish tinge of bile in the evacuations sooner than the others. I thought the lime-water, two parts, with one part boiled milk, mixed, did good, particularly with children; in all these cases the liniment. hydrarg. fort. was well and assiduously rubbed in ; and where the mouth was quickly made sore, they generally began to mend rapidly. In the stage of collapse I found blankets, flannel bandages, bottles of hot water, flat bags of bot salt, friction, counter extension where there was spasmodic contraction, and free ventilation, of great use; the-mercurial friction was kept up, the salt-and-water and toast-andwater were continued; isinglass in solution, with a little brandy and tr. opii, was injected, and cataplasms of mustard and spt. terebinth. were applied all along the spine, over the chest and abdomen, and to the feet; but $I$ did not think any external application of much use in this state.

In a few cases of bilious diarrhcea, I gave the nitrous acid mixture, with tr. opii, as recommended by Dr. Hope of Chatham; I thought it did good, but in cases of real cholera it entirely failed with me. Opium, brandy, cajeput oil, and all stimulants, hurried on the blue stage; calomel did no good. The disease should be called "spasmodic asphyxia."

Willitam Collyns, M.R.C.S. Kentor, near Exeter, Oct. 3rd, 1832. No. 477 .

\section{LETTER FROM DR. GILLKREST}

RESPECTING SOME STATEMENTS IN TUE

PAPER OF MR. ORTON,

$$
\text { At Page 43, No. } 475 \text {. }
$$

\section{To the Editor of The Lancet.}

Sir,-In the number of your journal for the 6th inst, there is a letter from Mr. Orton, in which reference is made to me in respect to a person who died of cholera in the Military Cholera Hospital, in Regentstreet, Vauxhall-road, the man baving first felt unwell, as is stated, while rubbing a cholera patient. Most disagreeable indeed it is to me, when thus calied upon by a gentleman with whom I have always been on the best terms, to be obliged to say that I felt perfectly astounded by the manner in which the circumstances connected with the above case have been sent forth to the public ; and your readers will probably not be less astonished than I have been, when they peruse the following statement.

On the 6th of August last, I was informed that a case, incontestably proving the contagious nature of cholera, had at last occurred under Mr. Orton, as his steward, or hospital-sergeant, had been attacked with the disease immediately after rubbing a patient. Well aware, from long experience, of the necessity of inquiring into such matters a little more closely, I gladly availed myself of the permission of $\mathrm{Mr}$. Orton, whom I saw immediately after, to accompany him to his hospital, a distance of about a mile and a half. On setting out, Mr. Orton said that " as it was but fair to state both sides of a question," he must admit that the man, contrary to his usual babits, had been drinking beer,-a circumstance which I observe has been forgotten by $\mathrm{Mr}_{\text {r }}$ Orton in his letter, though considered at the time, it would appear, as of importance. enough to be noticed ; for who will deny: importance even to trifling deviations froms the usual mode of living, during an epidemic. influence? Indeed I feel warranted in concluding that Mr. Orton's details bear strong; marks of having been hastily drawn up; for otherwise, I am sure, from my knowledge of this gentleman, that another cirn cumstance, perhaps of still more importan'ie, would not have been omitted,- - the ag $a$ of the man, which was sixty-five. I cert'dinly expected that, on my arrival at the hos,pital, I should bave found a stout sergear at of a regiment labouring under an attack, and I was not a little surprised to find that our patient was a worn-out Chelsea pansioner, who, though at forlorn hopes enough in his day, had still, it appeared, gallantry enough left not to object to the contagionists' for 
lorn hope,-the duty of a cholera hospi- day in question. The nurse, indeed, further tal. declared, in the presence of Mr. Glisson, I may be allowed to digress here, for a that Thomas Bray having been at Chelsea, moment, in order to mention, as one of the on his private affairs, for a part of the day on many proofs of the absurdity of those de- which Lyons was received into the hospital, scriptions of the true cholera, deemed he did not even see the latter for some time "graphic," that in the above man's case, after his admission; and she had the the pulse was perfectly natural, and the strongest belief (although it seems that the heat of skin not remarkably reduced, pensioner had given Mir. Orton a contrary although in other respects some most cha- impression) that she herself was the only racteristic symptoms presented themselves. person who had rubbed Lyons.

Relative to the period when this man " Relot "first felt unwell," and from which Mr. has been referred to by Mr. Orton, I have Orton thinks he is justified in drawing con- no besitation in declaring, as I did at the clusions important to science, as it seemed time to that gentleman, that the poor man to cost the patient much exertion to express who was also a pensioner, was decidedly la. himself when I saw him, I forbore ques- bouring under a panic; and this the nurse tioning him too closely, and referred to the declared, on the morning of the 8th iustant, nurse of the hospital for information as to to have been certainly the case, as she his habits, the precise time at which he "could hardly get him to go near the sick, first complained, \&c., and was told by her or even up.stairs where they were." MIr. that he had complained of being ill early in Orton will, I presume, be the less disposed the morning of the 4th of August. On hear- to doubt that the degree of illness under ing this I begged of Mr. Orton to accom. which this man lahoured bad been induced pany me again to the bed-side of the patient, by the cause just assigned, when he refor the purpose of asking him a single ques- collects the very curious details related tion, when the man admitted that he had about the time, by a regimental surgeon, in been unwell on the morning of the day just his presence, not of a worn-out pensioner mentioned. So altered did Mr. Orton's put out of his regular habits in fifty different views become, on this avowal, as well as ways, but of a soldier in the full vigour of probably from the great quantity of undigested, unmasticated, food which we saw had been vomited up, that he admitted, on the spot, that the circumstances connected with the case wore a different aspect. If any fresh reasons occurred to induce $\mathrm{Mr}$. Orton to return to his original opinion of the matter, he certainly never did me the favour to state what those reasons were, at any of the subsequent interviews which I had with him previous to bis leaving London.

As some of your readers may agree with $\mathrm{Mr}$. Orton in attacbing great importance to the periods at which the above man became first indisposed, I beg leave to subjoin a copy of a certificate, signed by a gentleman who bappened to be present when the nurse of the Cholera Hospital lately in that gentleman's charge, called upon me for the purpose of restating what she knew upon the subject :-

"London, October 8th, 1832.

"Ellenor Irwin, nurse at the Cholera Hospital in Regent-street, Vauxhall-road, has this morning Thomas Bray, a Chelsea pensioner, acting formerly
as hospital sergeant, complained to her of being ill early in the morning of the 4th of August last, being some hours before the admission of John Lyons, of the Coldstream Guards, on that day.

"JAMES GLisson,

Licentiate of the Company of Apothecaries."

John Lyons was the name of the man from whom the pensioner was said to have taken the disease, and who, according to Mr. Orton's notes in the hospital-book, was not admitted till half-past eleven of the youth, and belonging to one of the finest regiments in the world, having been taken suddenly and cery alarmingly $i l l$, on reading in a new neuspaper some distressing account of a cholera patient.

Mr. Orton has openly appealed to me in support of what be has stated respecting his hospital sergeant; a proof, in my mind, sufficient to establish, that, however his memory may have failed, his intentions were pure. It will be admitted, I hope, that when I saw he had been so greatly mistaken, I could not with any propriety remain silent. Amicus Plato, ơc.

Perhaps I may be allowed, by further reference to Mr. Orton's letter, to touch upon points really of the bighest importance to mankind. This gentleman says such facts as these, relative to the two pensioners, having passed before his eyes, would alone justify, had he not been previously influenced by the statements of others, his abandonment of bis former non-contagious, or, as he calls it, Indian creed. And thus reasons, during the cholera epidemic of 1832 in England, the author of a most excellent work, written some years ago in India; and in which, among many other valuable observations for our guidance, the immunity of attendants on cholera patients, was compared to what it would be in the case of attendants on so many wounded men! Had Mr. Orton given the public, as he so well might have done, the result of inquiries in the army circle to whioh be 


\section{RELATIVE TO CONTAGION IN CHOLERA.}

was particularly attached in London, it/sion and society to show that this, se would be seen how exactly things occurred seems to insinuate, was established $T$ : 1 on on the banks of the Thames, as he and so servations or inquiries within the circle to many others told us they occurred on the which his duties were confined. This howbanks of the Ganges. For, of the military ever I am quite sure he could not do; for and medical officers in contact with the having been a good deal among the medical cholera cases treated in the Tower hospital gentlemen whose men were treated in $\mathrm{Mr}$, of the Grenadier Guards since the middle of Orton's bospital, I could not hear from them June last (the time when I first saw cases there), of the many attendants of all classes on cholera patients there, since then, how many have had the disease? Nrot one. Of the several persons of all ranks and classes in attendance for some months on cholera patients in the hospital of the Grenadier Guards in Vauxhall-road, close to Mr. Orton's hospital, how many of those attacked? Not one. In the ordinary hospital of the 2nd Life Guards at Knightsbridge, where three fine fellows were obliged to be treated in August last, their cases being too desperate to admit of removal to Mr. Orton's hospital,-how many of the individuals who visited them, or were in constant attendance on them, have been since attacked? Not one. Not one attendant, \&c. attacked in all these instances, according to the result of my inquiries, and I have been at no small pains in endeavour. ing to ascertain. To expect that, during an epidemic, no attendants on sick should be attacked, independently of the agency of contagion, would be an utter absurdity; but as in the above instances of the Guards, and in a thousand other instances in London, the better the description of persons, and the more of them who are in attendance, the greater will the probability be of their never being attacked in a higher proportion than the average of the community not so employed.

'To MIr. Orton and all others of easy faith, several instances could be furnished in the metropolis, not only of tottering pensioners, but of the unfit from dissolute babits, of the delicate and teeble, more needing to be attended upon than able to attend others, who have, in cholera hospitals, as well as out of them, been attacked with the disease; and $I$ envy not the man who draws such conclusions as Mr. Orton does therefrom.

Mr. Orton had written, while in India, some years ago, a most excellent work on cholera, as before stated; and as his opinions now regarding the contagion of cholera may have a baneful influence not only in this country but in others, the data which he furnishes should therefore be subjected to proper tests. I shall not hesitate declaring, on a question of public interest lile the present, that Mr. Orton is not in any degree borne out in his assertion as to cholera never having arisen from other causes than contagion. Before maling so sweeping an assertion, he was bound towards the profes-

that they had traced contagion in a single in. stance. As Mr. Orton was present when some of my inquiries upon this point were made, (when, indeed, a surgeon of a regiment said that three men just attacked belonged to three different troops, and that the cause was inexplicable,) I am the more astonished.

But what more extraordinary, -Quousque tandem! - than to find Mr. Orton declaring, in the present day, and after so much ex. perience in the families of medical men and others in contact with sick, that he has "likewise seen reason to believe that the disease may be conveyed by persons who are themselves unaffected by it;" and his reason is certainly sufficient to make every nervous old lady in the land close her doors against medical men who have been near cholera patients. Mr. Orton (most philosophic reason truly!) found that, while he was attending cholera cases at his hospitals, some people living in the house where he lodged had diarrhœa. The force of this reason will be duly estimated by those who have at all attended to the epidemic influence during some months past, and who are so fully aware that scarcely a family, especially in the line of the river, has escaped attacks of diarrhœa, whether medical men were or were not inmates. A fact so well known (known indeed et lippis et tonsoribus), I was rather suprised to find had not been brought forward by Mr. Orton, anxious as he must be to give both sides of the question, in order that those people among whom these things have not yet occurred, may have an opportunity of exercising their common sense a little in the question. Mr. Orton's landlady, and some of her children, bad certainly a slight indisposition, such precisely as some of her neighbours had, with whom no professional man happened to lodge; and let a fact so important therefore stand recorded.

Mr. Orton asks, " Have not a great majority of medical men everywhere experienced the cholerine ?" If he means, which I suppose he does, the medical men who bave attended to their duty and seen cholera patients, then I can, I think, for London at least, answer, - Not in a greater proportion certainly than that in which others bave had an indisposition so called.

It augurs badly for science when we find such men as Mr. Orton labouring, by quot. 
ing ench places as Bilston and Sligo, to / valuable character; for never, we believe, show plow much more than others medical has a pestilence had more competent hismen cave suffered from cholera. He is, or torians than MM. Bouillaud and Gendrin, ought to be, well aware, that in all parts of the world where cholera has yet appeared, the peculiar epidemic influence which I know this gentleman admits, is observed to prevail with peculiar intensity at some points; and in such cases it would be as inadmissible to refer the attacks of medical men to the agency of contagion, as it would be, mutatis mutandis, in the instance of a malaria street in Rome. At Sligo and Bilston almost all those (quite all, according to some) who were in easy circumstances, left those places when the disease exploded so violently, except the medical men; nothing more easy, then, to an ingenious person, than to malie it appear that medical men, on the winding up of lists, had suffered probably more in proportion than that class of society to which they belonged.

Long as this letter is, I trust that you will give it insertion in your journal, as, upon mitters of high public importance, vague statements and but indifferent logic, should not be suffered to go forth unnoticed, even though they come from a gentleman for whom I have such a high respect as I have for Mr. Orton. I remain, Sir, your very humble servant,

London, Oct. 10, 1832.

J. Githkrest.

\section{Ihom, 0 ct. $10,1832$.}

Traite Pratique, Theorique, et Statistique du Cholera Morbus de Paris, \&c. Par J. Bounluavd, Médecin de l'Hôpital de la Pitié, \&c. Paris, Bailliere, 1832. 8vo. pp. 426.

Monographie du Cholera Morbus Epidemique de Paris, \&c. Par A. N. Gendrin, \&c. Paris, Bailliere, 1832. 8vo. pp. 336.

Cholera Morbus de Paris, \&c. Par A. F. H. FABRE, M.D. Bailliere, 1832. $12 \mathrm{mo}$. pp. 163.

Some months have elapsed since we promised, that when the fearful epidemic then devastating Paris should have ceased, and when the events of that memorable time should have been duly registered by the able observers of the scene, that our readers should be put in possession of an ample digest of all that had been noted down of the epidemic. In the present article we shall endeavour to redeem that pledge. In the attempt, we possess the advantage at least of having materials before us of the most and never, to our knowledge, did histories, so apidly written, evince more profundity of research, more power of induction, or greater excellence of description, than is demon. strated in every page of the volumes by hese distinguished authors.

The work of M. Bouillaud consists of three parts. In the first, which occupies 66 pages, the author describes ut great ength 50 fital cases of cholera. This part embraces two sections, one relative to cases of simple cholera, the other to that disease complicated with other affections. Each of hese sections is divided into various categories. In the cases of the first category, death supervened in the space of twentyfour hours. The cases of longer duration, but terminating before the appearance of consecutive fever, occupy the second. Finally, the third is devoted to cases terminating fatally during the typhoid period. In the second section of the first part, three categories are comprized, in which, 1st, The cases complicated with abdominal diseases; 2nd, Those with thoracic; and, Suly, Those with cephalic,-are consecutively arranged and described.

The second part is occupied by general history of the disease. It comprises seven sections; 1st. The causes and mode of propagation of the cholera; 2 . Its symptoms; 3. Its anatomical characters; 4. Its nature; 5 . Its mode of invasion, its duration, and its end; 6 . Its treatment; and 7 . Its mortality, and the prognosis to be advanced. 'The discussion of both these topics is guided by statistical researches.

The third and last part of the volume is composed of the narratives of 52 cases of recovery, arranged under the heads of collapse and typhoid. By this synoptical vie of the contents, the reader may perceive, that the author's arrangement is such as to afford him ample scope for generalisation and induction. It has the inestimable advantage of applying the method of analysis to the study of this most beterogeneous disease, and it thus entitles the author's clinical inferences to the serious attention of all those who wish to regard me dicine, as something beyond a conjectural and empiric art. 